\title{
Influence of water-soluble monomers on the corrosion protection ability of chromium coatings obtained from $\mathrm{Cr}$ (III)-based solutions
}

\author{
N.A. Vetlugin ${ }^{1}$ and N.A. Polyakov ${ }^{1,2 *}$ \\ ${ }^{1}$ Dmitry Mendeleev University of Chemical Technology of Russia, Miusskaya sq., 9, \\ Moscow, 125047 Russian Federation \\ ${ }^{2}$ A.N. Frumkin Institute of Physical Chemistry and Electrochemistry, Russian Academy \\ of Sciences, Leninskii pr., 31, Moscow, 119071 Russian Federation \\ *E-mail: grottopna@mail.ru
}

\begin{abstract}
The effect of water-soluble electropolymerizable monomer additives in $\mathrm{Cr}$ (III) sulfateoxalate electrolytes on the corrosion-electrochemical behavior of chromium coatings and their ability to protect the steel support is studied. The additives into the $\mathrm{Cr}$ (III) sulfateoxalate electrolytes were caprolactam, aniline, and acrylamide. The XPS technique showed that both the surface and bulk layers of chromium coatings obtained from electrolytes with additives contain products of chemical or electrochemical conversions of caprolactam, aniline, and acrylamide, including their polystructures. It is found that caprolactam and aniline produce a positive effect on the protective ability of chromium coatings, while the protective ability of chromium coatings in the presence of acrylamide decreases. These properties are determined primarily by a decrease in the number of defects in chromium coatings in case of caprolactam and aniline and an increase in the number of cracks in the deposits in case of acrylamide. According to the earlier studies, the corrosionelectrochemical behavior of chromium coatings from $\mathrm{Cr}$ (III) sulfate-oxalate electrolytes in $0.5 \mathrm{M} \mathrm{H}_{2} \mathrm{SO}_{4}$ is determined primarily by the presence of the chromium carbide phase acting as a cathodic agent. The effect of additives on the anodic polarization curve in $0.5 \mathrm{M}$ $\mathrm{H}_{2} \mathrm{SO}_{4}$ is most probably determined not only by an increase or decrease in the porosity of chromium deposits, but also by incorporation of the additives and products of their electrochemical conversion that, according to the literature, can act as corrosion inhibitors.
\end{abstract}

Keywords: chromium coatings, chromium plating, caprolactam, aniline, acrylamide.

Received: October 17, 2018. Published: November 9, 2018

doi: $\underline{10.17675 / 2305-6894-2018-7-4-6}$ 


\section{Introduction}

Electrolytic chromium plating remains as yet one of the most widely used processes in electroplating. The main functions of chromium coatings are related to their protective and decorative properties and enhancement of wear resistance of the surface of materials, primarily steel. As chromium in contact with steel is a cathode in most media, an important feature of chromium coatings is the presence of defects. It is well known that chromium coatings from $\mathrm{Cr}(\mathrm{VI})$-based electrolytes are characterized by through porosity even in case of rather large thicknesses of $\sim 20 \mu \mathrm{m}$ or more. Introduction of any organic additives improving the coating surface morphology or enhancing the protective properties into $\mathrm{Cr}(\mathrm{VI})$-based chromium plating electrolytes is problematic due to the high corrosivity of these solutions. In this case, copper or nickel sublayers are used to enhance the protective properties of chromium coatings on steel.

An alternative to $\mathrm{Cr}(\mathrm{VI})$-based chromium-plating electrolytes can be electrolytes based on Cr(III) compounds. Such electrolytes have already been developed long enough and some of them are commercially suitable for application of protective-decorative chromium coatings [1-6]. Chromium deposits from such electrolytes also have pores, but the lesser corrosivity of $\mathrm{Cr}$ (III) solutions allows introducing into them various organic additives.

In this work, additives of water-soluble monomers were added into the $\mathrm{Cr}$ (III) sulfate-oxalate electrolyte [6]: caprolactam, aniline, and acrylamide that are known both to produce a favorable effect on the functional properties of galvanic coatings, including corrosion resistance, and also to be corrosion-resistant by themselves.

Thus, addition of caprolactam into the copper plating [7-9], cadmium plating [10], and nickel plating [11] electrolytes noticeably affects the uniformity, morphology, and tribological behavior of coatings. Products of electrochemical conversion of polyaniline can successfully inhibit steel corrosion processes [12-14]. Acrylamide, same as the products of its polymerization, i.e., polyacrylamide and its copolymers, can also successfully inhibit, e.g., corrosion of steel in acidic and chloride-containing media [1517].

The aim of our work was to study the effect of caprolactam, aniline, and acrylamide additives in the $\mathrm{Cr}$ (III) sulfate-oxalate electrolyte on corrosion properties of the forming chromium coatings.

\section{Experimental}

A concentrated $\mathrm{Cr}$ (III) sulfate-oxalate electrolyte of the following composition (g/l) was used for electrodeposition of chromium coatings [6]: $\mathrm{KCr}\left(\mathrm{SO}_{4}\right)_{2} \cdot 12 \mathrm{H}_{2} \mathrm{O}-250$, $\mathrm{Al}_{2}\left(\mathrm{SO}_{4}\right)_{3} \cdot 18 \mathrm{H}_{2} \mathrm{O}-110, \mathrm{Na}_{2} \mathrm{C}_{2} \mathrm{O}_{4}-40, \mathrm{NaF}-17$. The solutions were prepared using twice distilled water with their following thermal treatment at $90^{\circ} \mathrm{C}$ for $30 \mathrm{~min}$ for stabilization of the complex composition. 
Additives of water-soluble caprolactam, aniline, and acrylamide monomers were added into this solution. The coating electrodeposition conditions were as follows. The solution temperature was $40^{\circ} \mathrm{C} ; \mathrm{pH} 1.1-1.2$; the cathodic current density was $35-$ $45 \mathrm{~A} / \mathrm{dm}^{2}$. The plating was performed without separation of the cathode and anode compartments. The anodes were platinum or platinized titanium.

Corrosion and electrochemical properties of the chromium coatings were studied using measurements of anodic polarization curves in solutions of $0.5 \mathrm{M} \mathrm{H}_{2} \mathrm{SO}_{4}$ in the potentiodynamic mode. The working electrodes were compact chromium deposits of different thickness on a Ni support with the visible surface area of $2 \mathrm{~cm}^{2}$. The choice of Ni as a support was aimed at minimization of the effect of the support on the results of measurements in case of the presence of pores and other coating defects and metal dissolution through them, as suggested in [18]. The measurements were carried out in a three-electrode cell. The auxiliary electrode was a platinum wire. The reference electrode was a saturated silver-silver chloride electrode. All values of potentials in the work are given vs. NHE. The potential of the working electrode was set using an IPCPro2000 potentiostat. The measurement program included cathodic surface pretreatment at the potential of $-0.65 \mathrm{~V}$ for $5 \mathrm{~min}$. Here, the current density was about $0.2 \mathrm{~A} / \mathrm{cm}^{2}$. Then anodic polarization was applied. Anodic polarization curves were measured in a potentiodynamic mode. The potential sweep rate was $5 \mathrm{mV} / \mathrm{s}$. The potential was varied from $-0.65 \mathrm{~V}$ to $+1.4 \mathrm{~V}$.

The porosity of coatings samples on low-carbon steel was controlled by applying filter paper impregnated by the test solution $(\mathrm{g} / \mathrm{l})$ : potassium ferricyanide -3 , sodium chloride -10 . The method is based on interaction between the support metal (iron) and test solution at the pore sites with formation of colored compounds (blue). The sample edges were additionally isolated. The sample control conditioning duration in the test medium was $5 \mathrm{~min}$.

The protective ability of chromium coatings with respect to the low-carbon steel was assessed in a Weiss SC/KWT salt spray chamber. The medium was a sodium chloride solution with the concentration of $(50 \pm 5) \mathrm{g} / \mathrm{dm}^{3}$. The salt spray dispersion degree was $1-$ $10 \mu \mathrm{m}\left(95 \%\right.$ of drops). The water content was $2-3 \mathrm{~g} / \mathrm{m}^{3}$. The temperature in the chamber was $35 \pm 2{ }^{\circ} \mathrm{C}$. The test continued until the first corrosion damage areas appeared on the working surface. Sample edges and regions that need not be controlled were protected by wax. Samples were placed vertically in the chamber with the spacing between samples and chamber walls of at least $100 \mathrm{~mm}$. The sample corrosion damage degree was estimated visually.

The surface morphology was studied using a JSMU3 scanning election microscope with a WINEDS analyzer.

The chemical composition of coatings was estimated using the X-ray photoelectron spectroscopy technique (XPS). X-Ray photoelectron (XP) spectra of the surface layers were registered using an OMICRONESCA+ spectrometer. The pressure in the analyzer 
chamber was below $8 \cdot 10^{-10}$ mbar. The emission source was an $\mathrm{Al}$ anode with the radiation energy of $1486.6 \mathrm{eV}$ and radiation power of $252 \mathrm{~W}$. The analyzer pass energy was $20 \mathrm{eV}$. To account for the sample charging, the XP peak positions were adjusted by referencing them to the $\mathrm{C} 1 \mathrm{~s}$ peak of hydrocarbon admixtures from the atmosphere with its binding energy assumed equal to $285.0 \mathrm{eV}$. The spectra were deconvoluted after subtracting the background signal determined according to the Shirley method [19]. The peak positions were determined with the accuracy of $\pm 0.1 \mathrm{eV}$.

\section{Results and Discussion}

The prior XPS studies of chromium coatings obtained from the $\mathrm{Cr}$ (III) sulfate-oxalate electrolyte showed that the surface deposit layer contained mainly a mixture of $\mathrm{Cr}_{2} \mathrm{O}_{3}$ and chromium hydroxide $\mathrm{Cr}(\mathrm{OH})_{3} \cdot 2 \mathrm{H}_{2} \mathrm{O}$ phases and also products of partial reduction of oxalates. The average surface film thickness estimated on the basis of the diminution of the photoelectron signal intensity was $\sim 30 \mathrm{~nm}[20,21]$.

As follows from analysis of XP spectra of the surface layers of chromium deposits obtained from electrolytes with caprolactam, aniline, and acrylamide additives (Figures 13 ), the spectra contain the N1s line that is absent from the spectra obtained from an additive-free solution. This can indicate inclusion of products of chemical or electrochemical conversion of the additives in the solution into the coating. A layer-bylayer XPS study of the deposit chemical composition after ion etching to the depth of up to $30 \mathrm{~nm}$ shows that the coating surface contains, apart from chromium, organic compounds of carbon, oxygen, and nitrogen that are registered not only in the surface layer, but also in the coating bulk.

Analysis of the distribution of the $\mathrm{C} 1 \mathrm{~s}$ spectral line from the surface of coatings obtained from electrolytes containing additives in the high binding energy range shows that there is a shoulder related to superimposition of weak lines with higher energies that can be attributed to the $\mathrm{C}=\mathrm{O}, \mathrm{C}-\mathrm{N}-\mathrm{C}, \mathrm{C}-\mathrm{N}=\mathrm{C}$, and $\mathrm{C}-\mathrm{N}$ bonds. The $\mathrm{N}-\mathrm{C}=\mathrm{O}, \mathrm{C}-\mathrm{N}-\mathrm{C}$ $(399.8 \mathrm{eV})$ and $\mathrm{C}-\mathrm{N}, \mathrm{C}-\mathrm{N}-\mathrm{H}(401.2 \mathrm{eV})$ bonds are also registered using the $\mathrm{N} 1 \mathrm{~s}$ line. When acrylamide is introduced into electrolyte, the XPS spectra contain a low-energy peak that can be attributed to the $\mathrm{Cr}-\mathrm{N}$ bond. The presence of the $\mathrm{Cr}-\mathrm{N}$ bond in the XPS spectra can be related to formation of complexes between the additives and chromium ions in the electrolyte that can be included into the coating in the course of chromium electrodeposition.

The ionic etching of the surface of coatings applied from the aniline-containing electrolyte results in appearance of a peak in the region of $403.0 \mathrm{eV}$ that can be attributed to the $\mathrm{C}_{6} \mathrm{H}_{4}-\mathrm{NH}$ bond. As follows from the assembly of peals observed in the region of 403.0, 399.8, and 397.6 eV in the N1s XPS spectra from the surface of the coating obtained from the aniline-containing solution, one can conclude that products of chemical or electrochemical conversion of aniline, including its polystructures, are incorporated into the coating [22]. 


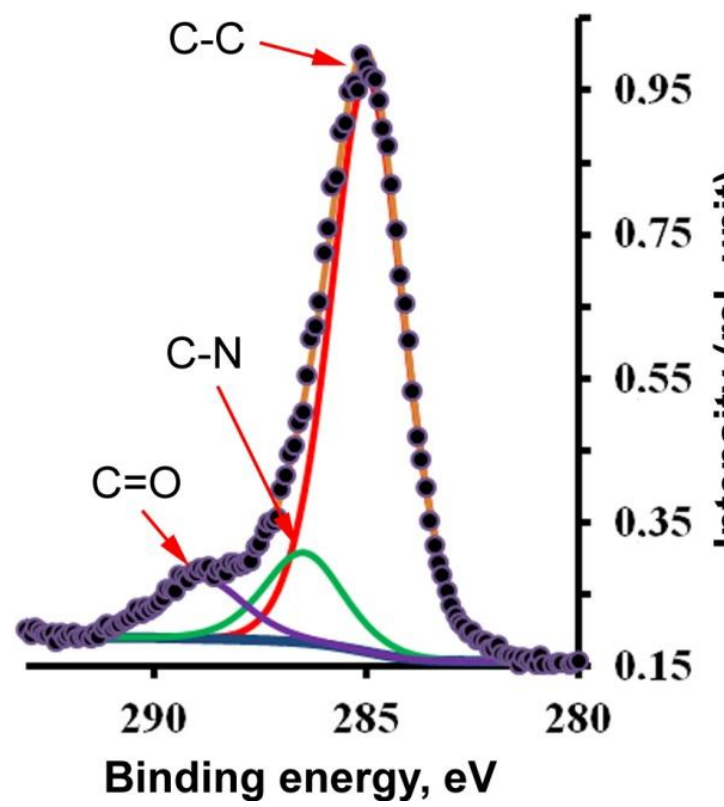

a

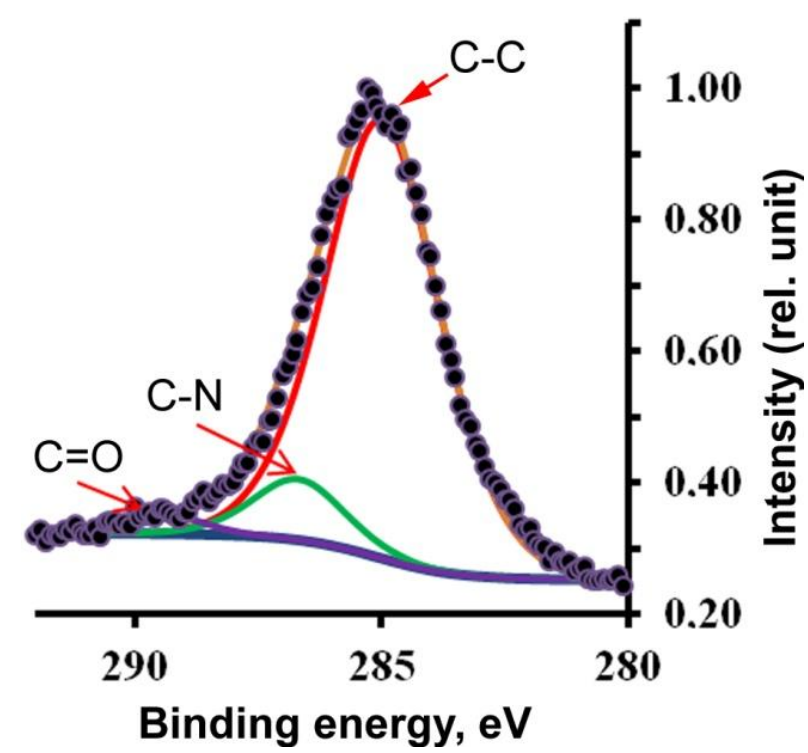

c

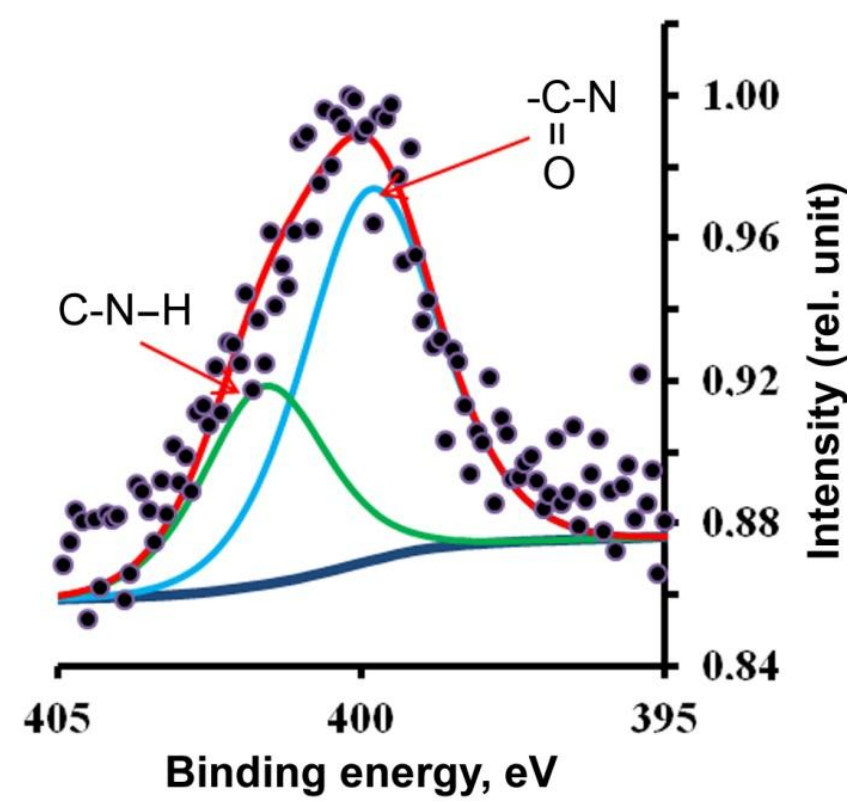

b

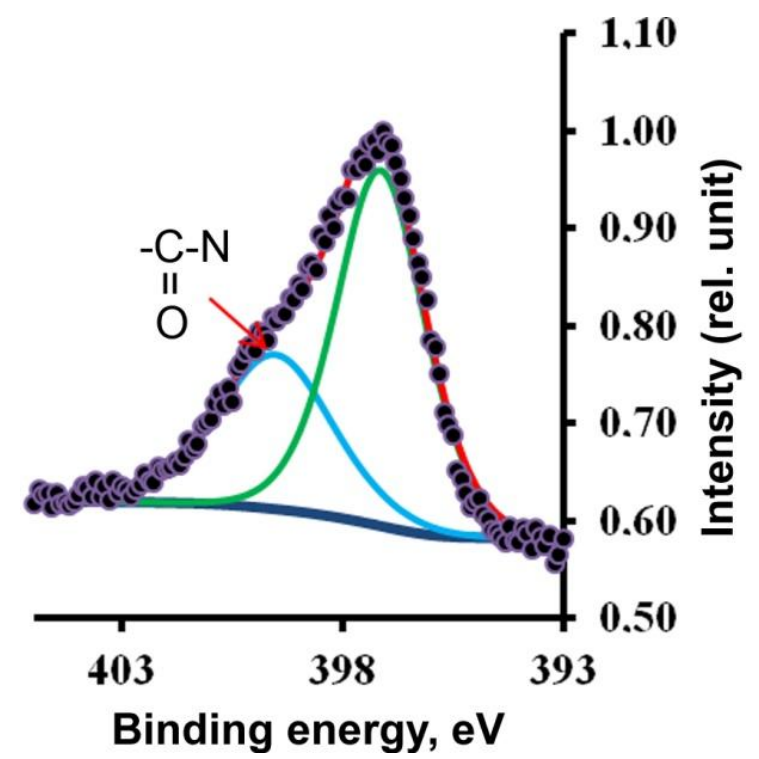

d

Figure 1. XPS spectra before $(a, b)$ and after $(c, d)$ the ion etching of the coating surface obtained from the sulfate-oxalate electrolyte containing $0.5 \mathrm{~g} / \mathrm{l}$ of caprolactam: (a, c) $\mathrm{C} 1 \mathrm{~s}$; (b, d) N1s. 


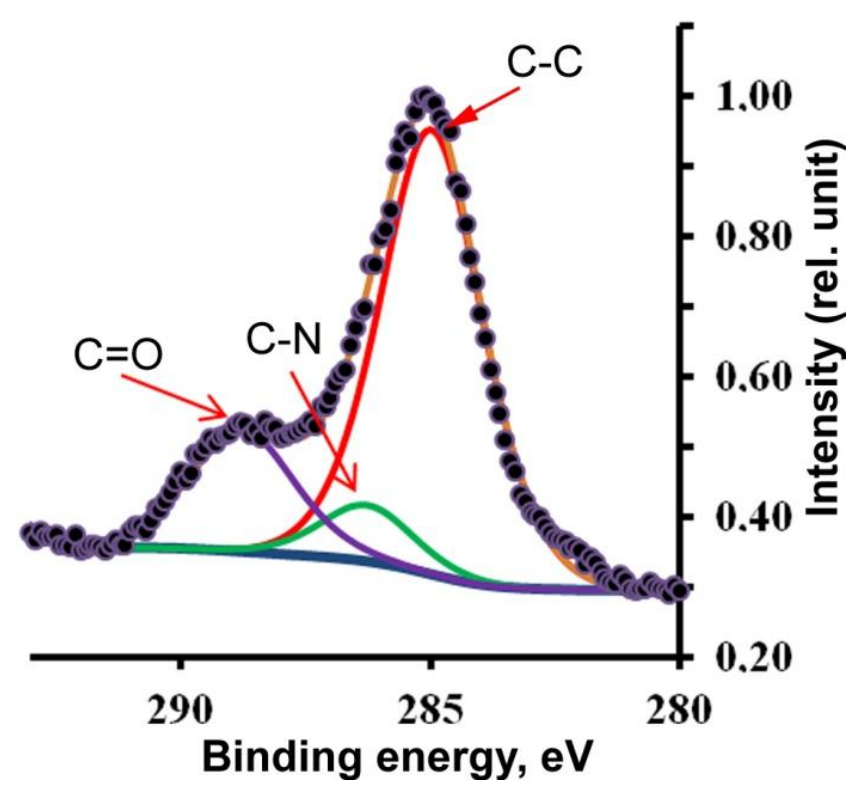

a

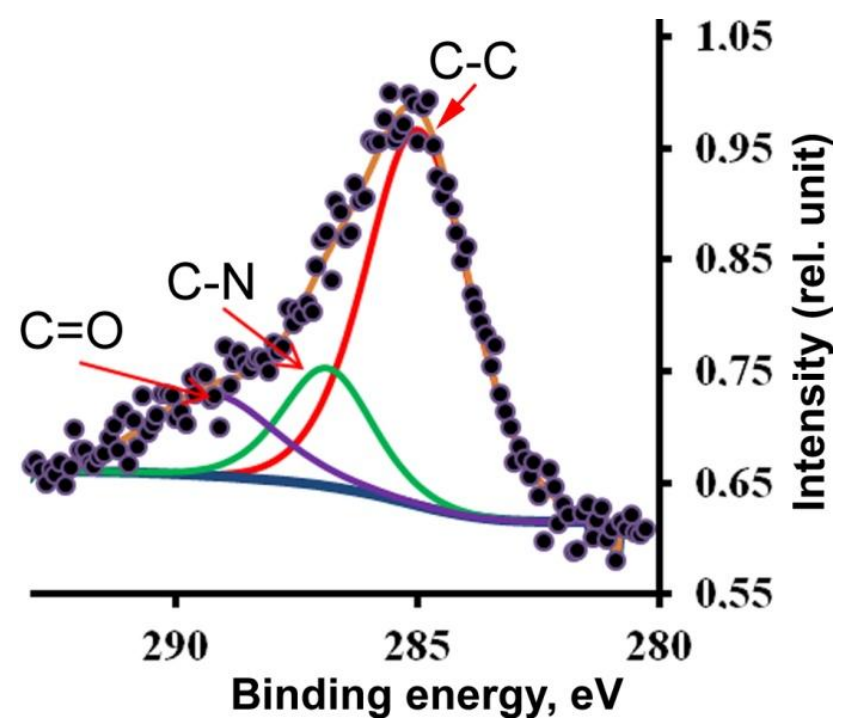

c

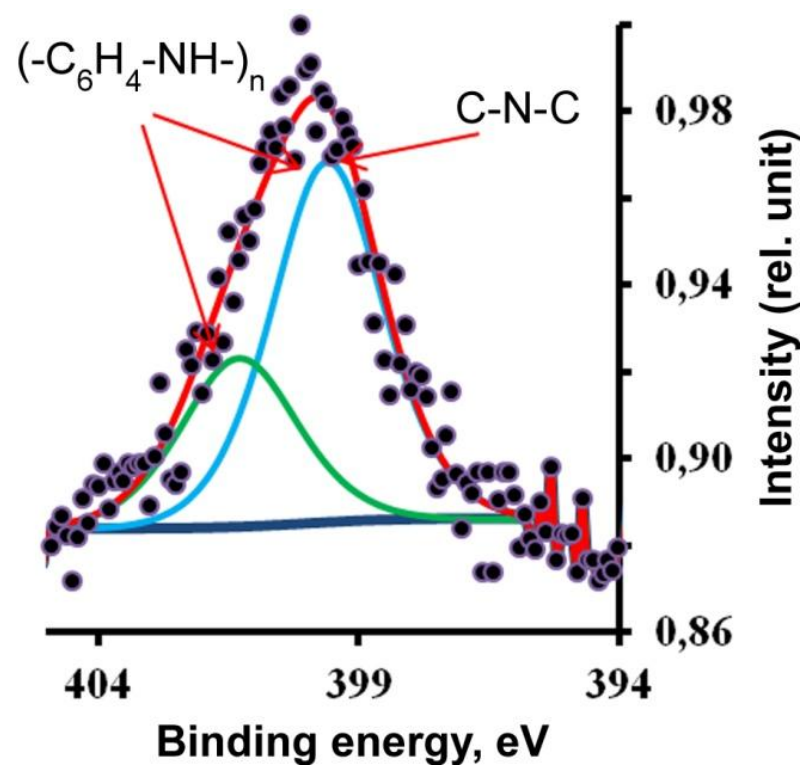

b

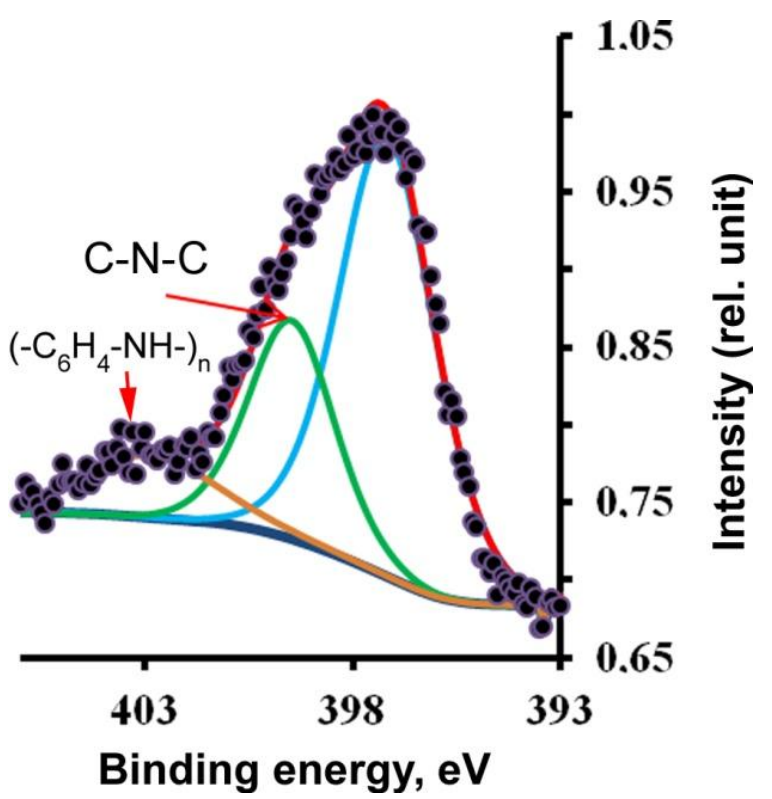

d

Figure 2. XPS spectra before $(a, b)$ and after $(c, d)$ the ion etching of the coating surface obtained from the sulfate-oxalate electrolyte containing $0.5 \mathrm{~g} / \mathrm{l}$ of aniline: $(\mathrm{a}, \mathrm{c}) \mathrm{C} 1 \mathrm{~s}$; $(b, d)$ N1s. 


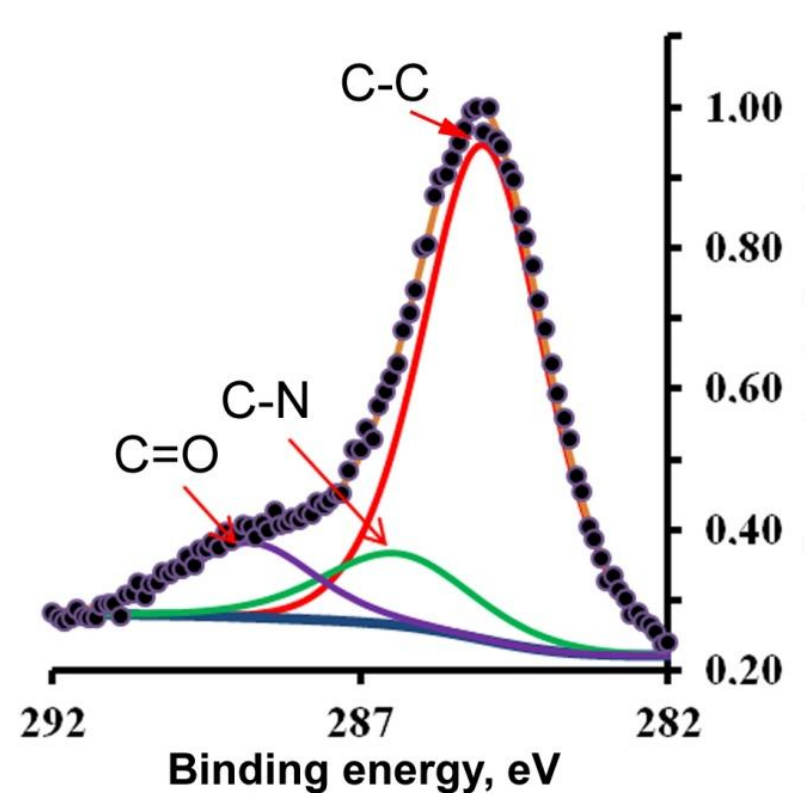

a

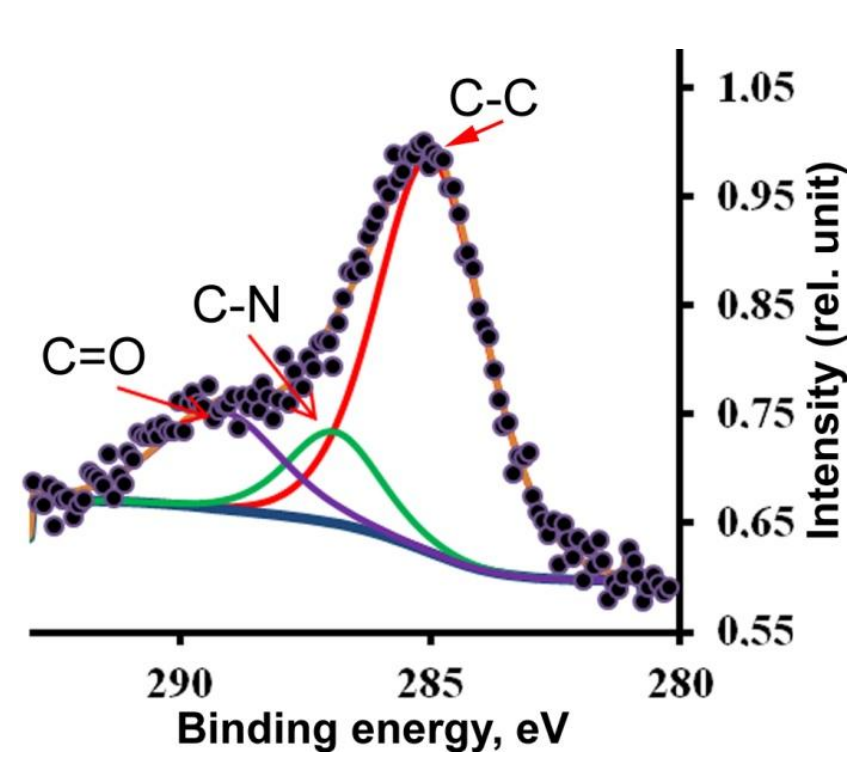

c

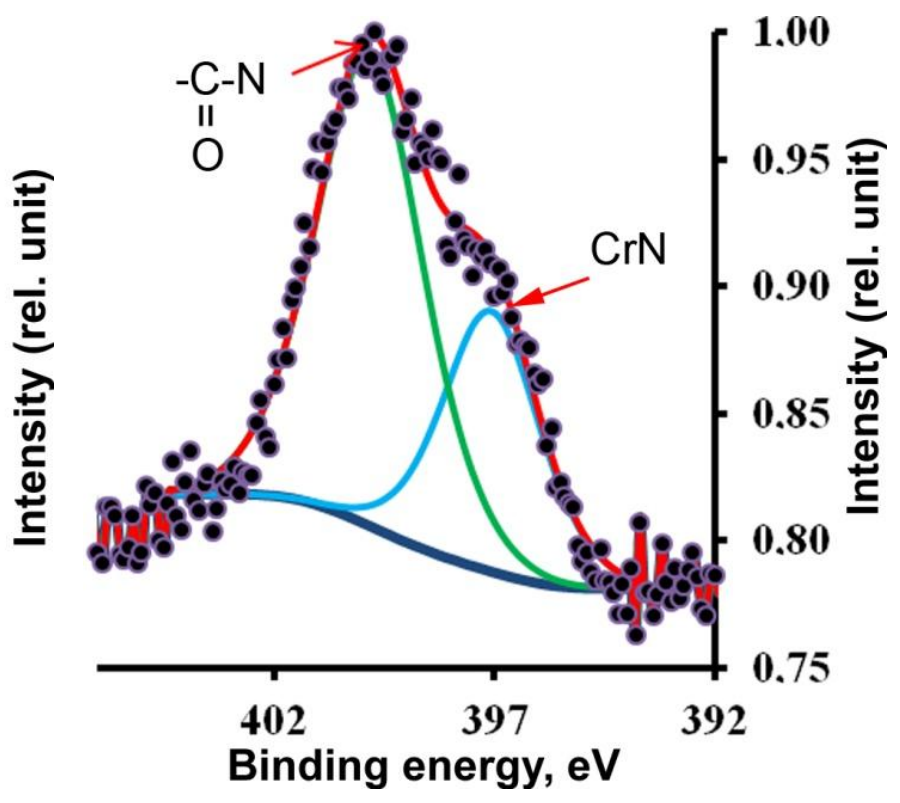

b

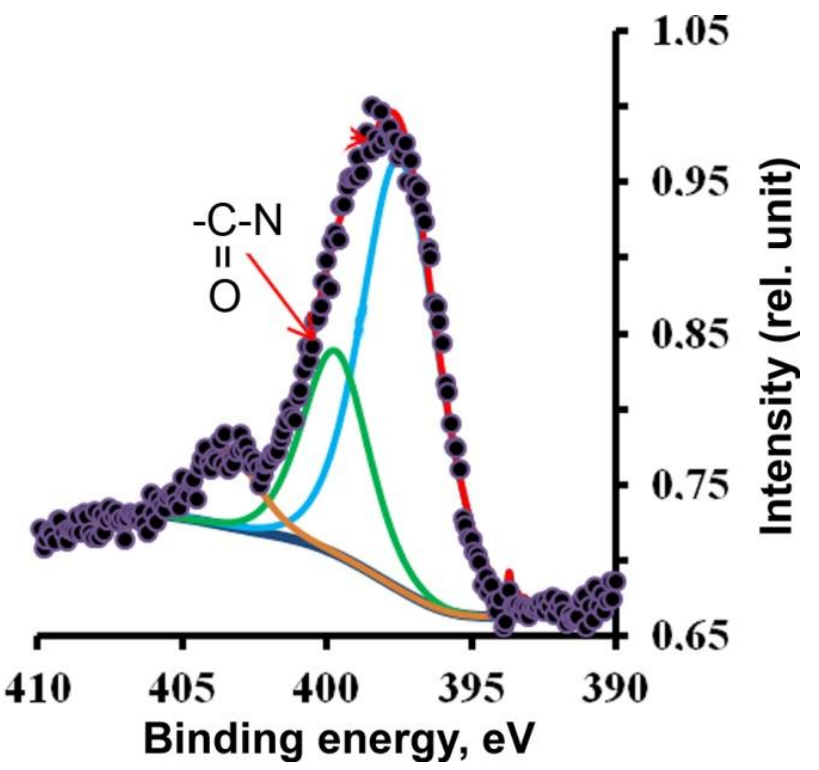

d

Figure 3. XPS spectra before $(a, b)$ and after $(c, d)$ the ion etching of the coating surface obtained from the sulfate-oxalate electrolyte containing $0.5 \mathrm{~g} / \mathrm{l}$ of acrylamide: (a) $\mathrm{C} 1 \mathrm{~s}$; (b) N1s.

The N1s XPS spectra obtained for the coating from the acrylamide-containing solution feature two peaks in the range of 403.7 and $399.8 \mathrm{eV}$ that can be attributed to polyacrylamide and polyamide structures according to the literature [23].

Figure 4 shows anodic polarization curves in $0.5 \mathrm{M} \mathrm{H}_{2} \mathrm{SO}_{4}$ for chromium coatings of different thickness obtained from $\mathrm{Cr}$ (III) sulfate-oxalate solutions containing caprolactam, aniline, and acrylamide. It was shown earlier $[18,20]$ that the corrosion-electrochemical 
behavior of the chromium coatings obtained from the $\mathrm{Cr}$ (III) sulfate-oxalate solutions in $0.5 \mathrm{M} \mathrm{H}_{2} \mathrm{SO}_{4}$ is characterized by the absence of the region of active chromium dissolution, which is determined by the presence of the chromium carbide phase in the coatings [24] that acts as a cathodic additive. The observe increase in the currents in the range of 350$400 \mathrm{mV}$ corresponds to dissolution of the nickel support through the coating defects [18]. Addition of caprolactam, aniline, and acrylalamide into the $\mathrm{Cr}$ (III) sulfate-oxalate solution does not noticeably affect the general shape of the anodic polarization curves. At the same time, much lower currents are registered in the range of potentials corresponding to dissolution of the nickel support for coatings obtained from the solutions containing additives, which probably points either to a decrease in the deposit imperfection degree or to inhibition of the corrosion process by the organic coating component. The observed decrease in the anodic currents for thicker coatings is apparently also related to a decrease in the number of through pores with the growing thickness of the deposit.

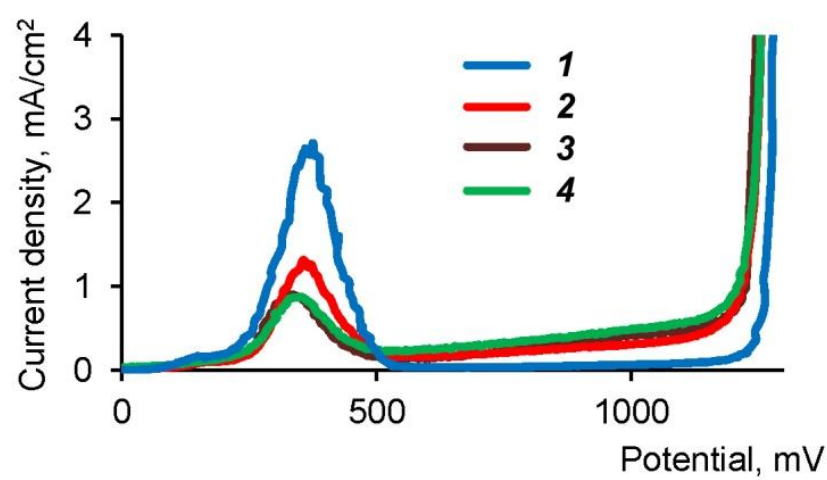

a

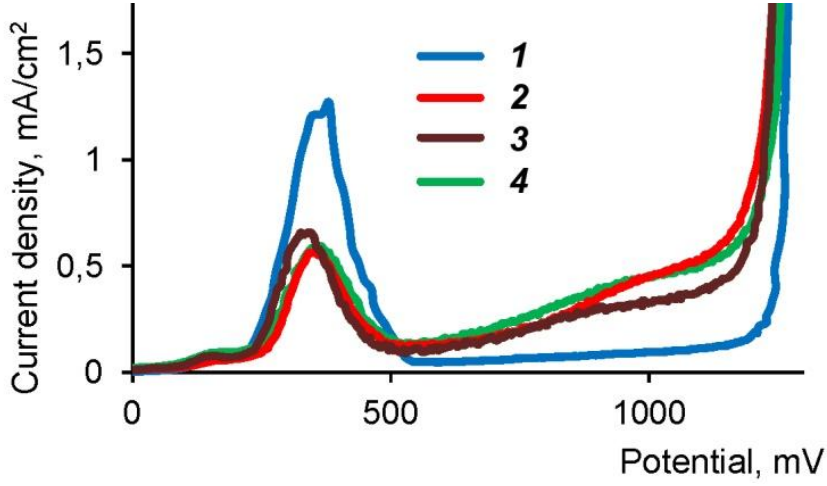

b

Figure 4. Anodic polarization curves of dissolution in $0.5 \mathrm{M} \mathrm{H}_{2} \mathrm{SO}_{4}$ of (a) 5 and (b) $10 \mu \mathrm{m}$ thick chromium coatings obtained from the $\mathrm{Cr}(\mathrm{III})$ sulfate-oxalate electrolyte: (1) with no additives; (2) with $0.5 \mathrm{~g} / \mathrm{l}$ of caprolactam; (3) with $0.5 \mathrm{~g} / \mathrm{l}$ of aniline; (4) with $0.5 \mathrm{~g} / \mathrm{l}$ of acrylalamide.

Indeed, analysis of the surface morphology of chromium coatings shows that caprolactam and aniline additives promote a decrease in the amount and size of pores in the deposit, as compared to the coatings from additive-free solutions (Figures 5a-5c). Besides, these additives cause a considerable smoothening of the coating surface morphology.

At the same time, addition of acrylamide into the $\mathrm{Cr}$ (III) sulfate-oxalate solution results in a fundamental change in the surface morphology of chromium deposits (Figure 5b). The additive apparently causes an increase in the internal stress in the coatings and eventually their cracking.

Here, the corrosion potential of chromium coatings obtained from the $\mathrm{Cr}$ (III) sulfateoxalate solutions containing caprolactam, aniline, and acrylamide in $0.5 \mathrm{M} \mathrm{H}_{2} \mathrm{SO}_{4}$ is shifted towards more positive potentials as compared to the corrosion potential of additivefree chromium coatings (Table 1). 


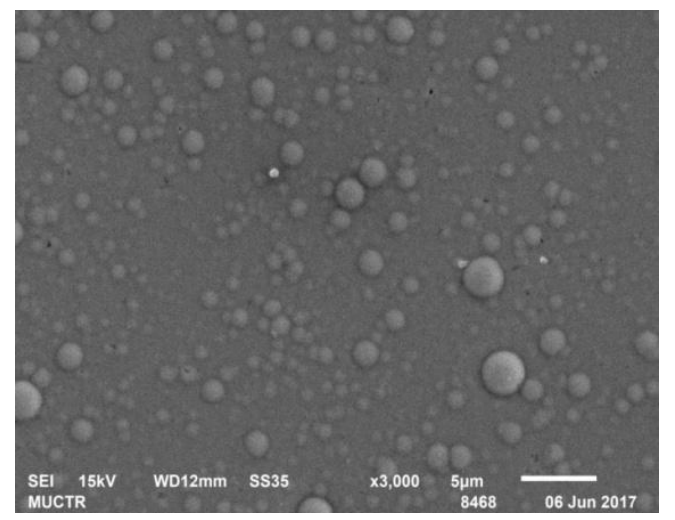

$\mathbf{a}$

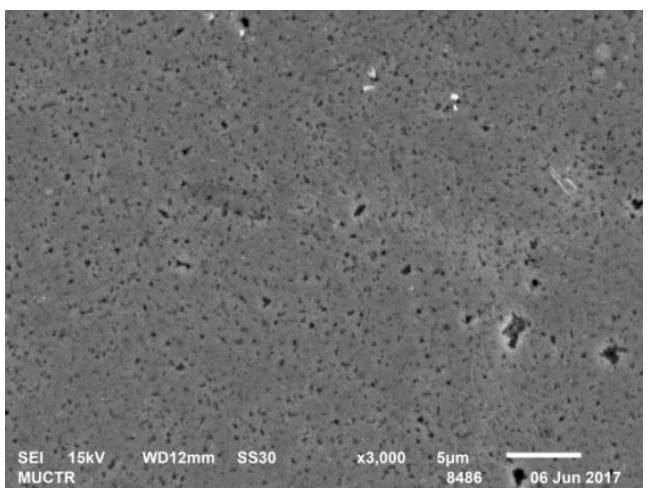

c

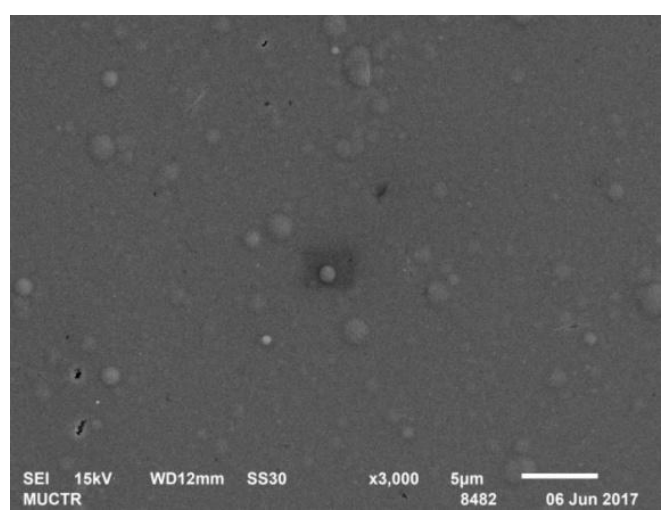

b

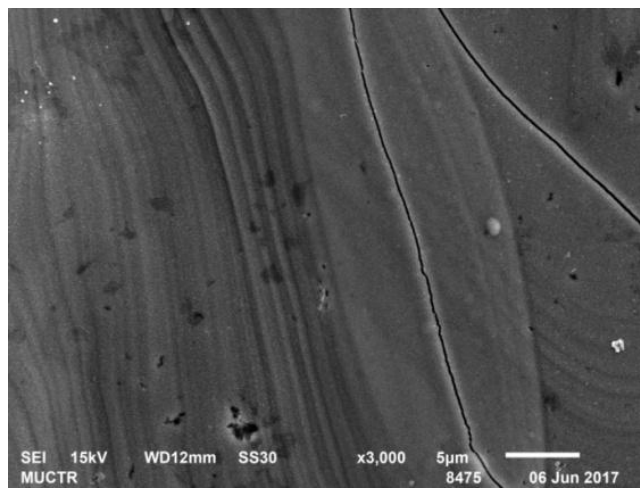

d

Figure 5. Morphology of $10 \mu \mathrm{m}$ thick chromium coatings obtained from the $\mathrm{Cr}(\mathrm{III})$ sulfateoxalate electrolyte: (1) with no additives; (2) with $0.5 \mathrm{~g} / \mathrm{l}$ of caprolactam; (3) with $0.5 \mathrm{~g} / \mathrm{l}$ of aniline; (4) with $0.5 \mathrm{~g} / \mathrm{l}$ of acrylalamide.

Table 1. Corrosion potential of chromium coatings obtained from the $\mathrm{Cr}$ (III) sulfate-oxalate solutions containing caprolactam, aniline, and acrylamide in $0.5 \mathrm{M} \mathrm{H}_{2} \mathrm{SO}_{4}$

\section{Material}

Support (nickel)

Coating obtained from the additive-free solution

Coating obtained from the solution containing $0.5 \mathrm{~g} / \mathrm{l}$ of aniline

Coating obtained from the solution containing $0.5 \mathrm{~g} / \mathrm{l}$ of caprolactam

Coating obtained from the solution containing $0.5 \mathrm{~g} / \mathrm{l}$ of acrylamide
Corrosion potential, $\mathbf{m V}$

$$
\begin{gathered}
80-120 \\
40-85 \\
170-188 \\
100-120 \\
120-138
\end{gathered}
$$

The effect of caprolactam on the porosity of the chromium coatings was studied as dependent on the chromium coating thickness and additive concentration in the electrolyte. As well seen from the data in Table 2, the porosity of the chromium deposits decreases on the whole at an increase in the concentration of the caprolactam additive in the electrolyte and also at an increase in the coating thickness, which agrees with the conclusions obtained from analysis of anodic polarization curves. 
Table 2. Porosity of chromium coatings of different thickness obtained from the $\mathrm{Cr}$ (III) sulfate-oxalate solution with the caprolactam additive.

\begin{tabular}{cccc}
\hline \multirow{2}{*}{$\begin{array}{c}\text { Concentration } \\
\text { of caprolactam, } \mathbf{g} / \mathbf{l}\end{array}$} & $\mathbf{3}$ Porosity, units per $\mathbf{~ c m}^{\mathbf{2}}$ \\
\cline { 2 - 4 } & $\mathbf{3} \mathbf{m}$ & $\mathbf{5} \boldsymbol{\mu \mathbf { m }}$ & $\mathbf{1 0} \boldsymbol{\mu \mathbf { m }}$ \\
\hline 0 & 17 & 8 & 4.5 \\
0.25 & 10 & 5 & 3 \\
0.5 & 7 & 5 & 2.5 \\
0.75 & 6 & 2 & 1 \\
\hline
\end{tabular}

Addition of up to $0.5 \mathrm{~g} / \mathrm{l}$ of aniline into the electrolyte caused no significant change in the porosity of the chromium coatings (Table 3). Meanwhile, the porosity of the chromium coatings increased in the presence of the acrylamide additive. It should be pointed out that the pore size in the coatings obtained from the aniline-containing electrolyte as compared to the coatings obtained from the additive-free electrolyte, all other conditions being equal.

Table 3. Porosity of chromium coatings of different thickness obtained from the $\mathrm{Cr}$ (III) sulfate-oxalate solution with the aniline and acrylamide additives.

Porosity, units per $\mathrm{cm}^{2}$

Coating thickness, $\mu \mathrm{m}$

Additive-free

with $0.5 \mathrm{~g} / \mathrm{l}$ of aniline

with $0.5 \mathrm{~g} / \mathrm{l}$ of

acrylamide

\begin{tabular}{cccc}
\hline 5 & 8 & 6 & 13 \\
10 & 4.5 & 3.5 & 7 \\
\hline
\end{tabular}

Tests of the protective ability of chromium coatings obtained the $\mathrm{Cr}$ (III) sulfateoxalate electrolyte containing caprolactam, aniline, and acrylamide in a salt spray chamber yielded ambiguous results. The first corrosion damage areas (in the steel support) in the $10 \mu \mathrm{m}$ chromium coatings obtained from the additive-free electrolyte and with $0.25-$ $0.50 \mathrm{~g} / \mathrm{l}$ of caprolactam are observed already after $2 \mathrm{~h}$ of tests, while those from the electrolyte with $0.75 \mathrm{~g} / \mathrm{l}$ caprolactam are registered in $3 \mathrm{~h}$. It should be pointed out that the corrosion damage areas on coatings from caprolactam-containing electrolytes during the further tests. The overall number of corrosion damage areas on these samples is even lower than on $25 \mu \mathrm{m}$ thick coating samples obtained from the additive-free electrolyte.

Corrosion on $10 \mu \mathrm{m}$ thick chromium coating samples obtained from electrolytes with $0.5 \mathrm{~g} / \mathrm{l}$ of aniline is observed after $4 \mathrm{~h}$ of tests in a salt spray chamber. However, corrosion damage areas on such samples are much smaller than on coating samples obtained from the additive-free electrolytes. 
On the contrary, addition of acrylamide into the $\mathrm{Cr}$ (III) sulfate-oxalate electrolyte impairs the protective ability of chromium coatings on steel. The overall number and size of corrosion damage areas on such coating samples after tests in the salt spray chamber are much larger than in case of coatings obtained from the additive-free electrolyte. This result agrees well with the data on the increase in the degree of imperfection of chromium deposits as a result of addition of acrylamide into the electrolyte.

Thus, studies of the influence of additives of water-soluble monomers in $\mathrm{Cr}$ (III) sulfate-oxalate electrolytes on the corrosion properties of chromium deposits demonstrate a positive effect of caprolactam and aniline on the protective ability of coatings on steel and a negative effect of acrylamide. These properties are determined in the first instance by the degree of imperfection of such coatings. The effect of the additives on the corrosion electrochemical behavior of coatings in $0.5 \mathrm{M} \mathrm{H}_{2} \mathrm{SO}_{4}$ is most probably determined not only by a decrease or increase in the porosity of chromium deposits, but also by incorporation of the additives themselves and of the products of their electrochemical conversion that can, according to the literature, act as corrosion inhibitors.

\section{References}

1. S. Survilienè, O. Nivinskienė, A. Češunienė and A. Selskis, J. Appl. Electrochem., 2006, 36, 649-654. doi: 10.1007/s10800-005-9105-8

2. M. El-Sharif, S. Ma and C.U. Chisholm, Trans. IMF, 1995, 73, 19-25. doi: 10.1080/00202967.1995.11871049

3. F.I. Danilov, V.S. Protsenko, T.E. Butyrina, E.A. Vasil'eva and A.S. Baskevich, Prot. Met., 2006, 42, 560-569. doi: 10.1134/S0033173206060075

4. S. Survilienė, V. Jasulaitienè, O. Nivinskienė and A. Češūnienè, Appl. Surf. Sci., 2007, 253, 6738-6743. doi: 10.1016/j.apsusc.2007.01.122

5. S. Surviliene, A. Lisowska-Oleksiak, A. Selskis and A. Češuniene, Trans. IMF, 2006, 84, 241-245. doi: 10.1179/174591906x130293

6. A.A. Edigaryan and Yu.M. Polukarov, Prot. Met., 1998, 34, 95-100.

7. V.V. Kuznetsov, L.M. Skibina, I.N. Loskutnikova A.I. Sokolenko and E.A. Sukholentsev, Prot. Met., 2003, 39, 150-153. doi: 10.1023/A:1022946911598

8. L.M. Skibina, V.V. Kuznetsov and A.I. Sokolenko, Prot. Met., 2003, 39, 235-240. doi: 10.1023/A:1023911002940

9. M.I. Mazuritskiy, S.I. Duimakaev and L.M. Skibina, J. Synch. Investig., 2014, 8, 767-774. doi: $10.1134 /$ S1027451014040284

10. V.V. Kuznetsov, L.M. Skibina, A.I. Sokolenko, I.N. Loskutnikova, A.S. Kuzharov and V.S. Bolotnikov, Prot. Met., 2004, 40, 310-315. doi: 10.1023/B:PROM.0000036949. 29715.59

11. L.M. Skibina, V.V. Kuznetsov and E.A. Sukholentsev, Prot. Met., 2001, 37, 159-162. doi: 10.1023/A:1010330222922

12. D.W. DeBerry, J. Electrochem. Soc., 1985, 132, 1022-1026. doi: $10.1149 / 1.2114008$ 
13. T.D. Nguyen, T.A. Nguyen, M.C. Pham, B.Piro, B. Normand and H. Takenouti, J. Electroanal. Chem., 2004, 572, 225-234. doi: 10.1016/j.jelechem.2003.09.028

14. M. Galkowski, M.A. Malik, P. Kulesza, H. Bala, K. Miecznikowski, R. Wlodarczyk, L. Adamczyk and M. Chojak, J. Electrochem. Soc., 2003, 150, B249-B253. doi: $\underline{10.1149 / 1.1567266}$

15. M.A. Elmorsi, Corros. Sci., 1998, 41, 305-320. doi: 10.1016/s0010-938x(98)00124-3

16. S.A. Umoren, Y. Li and F.H. Wang, Corros. Sci., 2010, 52, 1777-1786. doi: 10.1016/j.corsci.2010.01.026

17. B.D.B. Tiu and R.C. Advincula, React. Funct. Polym., 2015, 95, 25-45. doi: 10.1016/j.reactfunctpolym.2015.08.006

18. V.A. Safonov, L.N. Vykhodtseva, A.A. Edigaryan, A.D. Aliev, E.B. Molodkina, A.I. Danilov, E.N. Lubnin and Yu.M. Polukarov, Russ. J. Electrochem., 2001, 37, 127-134. doi: 10.1023/A:1009071622727

19. D.A. Shirley, Phys. Rev. B, 1972, 5, 4709-4714. doi: 10.1103/physrevb.5.4709

20. A.A. Edigaryan, V.A. Safonov, E.N. Lubnin, L.N. Vykhodtseva, G.E. Chusova and Yu.M. Polukarov, Electrochim. Acta, 2002, 47, 2775-2786. doi: 10.1016/S00134686(02)00163-9

21. N.A. Polyakov, Y.M. Polukarov and V.N. Kudryavtsev, Prot. Met. Phys. Chem. Surf., 2010, 46, 75-81. doi: 10.1134/S2070205110010119

22. S.N. Kumar, G. Bouyssoux and F. Gaillard, Surf. Interface Anal., 1990, 15, 531-536. doi: $10.1002 /$ sia.740150906

23. G. Beamson and D. Briggs, High Resolution XPS of Organic Polymers: The Scienta ESCA300 Database, Chichester, Wiley, 1992.

24. V.A. Safonov, L.N. Vykhodtseva, Yu.M. Polukarov, O.V. Safonova, G. Smolentsev, M. Sikora, S.G. Eeckhout and P. Glatzel, J. Phys. Chem. B, 2006, 110, 23192-23196. doi: $10.1021 / \mathrm{jp} 064569 \mathrm{j}$ 